\title{
SPECIAL REFRACTORIES FOR USE AT HIGH TEMPERATURE
}

\author{
By Wm. H. Swanger and Frank R. Caldwell
}

\section{ABSTRACT}

The choice of the most suitable refractory for the laboratory melting of pure metals at temperatures from $1,700^{\circ}$ up to $2,200^{\circ}$ C. without detrimental contamination of the metal by the refractory depends upon a number of factors, such as the stability of the refractory at the higher temperatures, the means available for forming and firing of crucibles, the type of melting furnace, chemical action of the particular metal in question, etc.

Methods are described in detail for the preparation of erucibles and other shapes from the oxides of thorium, magnesium, zirconium, and beryllium.

Thorium oxide, with a melting point above $3,000^{\circ} \mathrm{C}$., is the most refractory of the four oxides named. The method used for fusing this oxide is described. Crucibles made of fused thorium oxide have been used in the determinations of the melting points of platinum and rhodium.

Crucibles of the commercial fused magnesium oxide are not satisfactory for work with metals of the highest purity, but crucibles prepared from the so-called "C. P." or reagent grade of powdered magnesium oxide have been used at teinperatures up to $2,000^{\circ} \mathrm{C}$. without detrimental effect upon the metal melted.

The commercial electrically fused or sintered zirconium oxide contains small amounts of silica. Crucibles of this material have been used at temperatures up to $2,000^{\circ} \mathrm{C}$., but unless the melting is done in air, there is danger of contamination of the metal by the silicon in the refractory.

From a few experiments made with a small amount of the very pure oxide there are indications that, if available commercially, beryllium oxide might be a satisfactory refractory for use at high temperatures.

\section{CONTENTS}

I. Introduction

II. General considerations

III. Thorium oxide.

1. Crucibles of unfused thorium oxide

2. Procedure for fusing thorium oxide

3. Forming of special shapes from fused thorium oxide

IV. Magnesium oxide

1. Commercial fused magnesium oxide............... 1139

2. Chemical reagent grade of magnesium oxide

V. Zirconium oxide

1. "Slip-cast" crucibles._. 1140

2. Tamped and pressed crucibles.... 1141

VI. Beryllium oxide
VII. Summary

\section{INTRODUCTION}

An ever-present requirement in working with pure metals is a suitable crucible in which they may be melted without contumination. The choice of the most suitable refractory material for the laboratory melting of pure metals or alloys depends upon factors which are somewhat different from those governing the choice of refractories for commercial melting. For example, the cost of the material is not or- 
dinarily of particular importance. The refractory oxides discussed in this paper are considered as research materials, and if they satisfy other requirements made of them their cost is of secondary importance.

Where the maintenance of extreme purity of the metals to be melted is required it is generally more satisfactory or even quite necessary to make the crucibles in the laboratory rather than to attempt to use commercial crucibles. Then the procedures necessary and means available for the fabrication of the required shapes are factors to be considered. The type of furnace, the temperature to which the metal is to be heated, and the effect of the refractory material upon the purity of the metal are important factors in the choice of refractories.

Pure graphite is a very satisfactory refractory material for the melting of metals which do not combine with it. It is one of the most refractory materials and can be purchased in the form of bars or rods from which various shapes can be readily machined. However, the use of graphite is limited from the fact that it combines with many molten metals, and that it oxidizes rapidly at the higher temperatures.

There are available several refractory oxides which are inert to most molten metals, even at the higher temperatures. The results obtained with magnesium oxide, zirconium oxide, and zirconium silicate crucibles for melting pure metals have been reported in a previous publication from this bureau. ${ }^{1}$ Additional information that has been secured on these materials since that time, the use of thorium oxide crucibles for melting platinum and other metals of the platinum group, and a few observations on the suitability of beryllium oxide as a refractory material are recorded in the present paper.

These materials are not discussed from a strictly ceramic viewpoint. It is intended merely to describe the methods in use in the National Bureau of Standards laboratories for preparing refractory shapes in which to heat metals or alloys of the highest purity to temperatures up to $2,200^{\circ} \mathrm{C}$. without contamination from the refractory.

\section{GENERAL CONSIDERATIONS}

The first and most obvious requirement for a crucible is, of course, that it shall not soften or collapse at the temperature at which it is to be used. The melting points of thorium oxide and beryllium oxide have not been exactly determined as yet. Probably the statement that the melting point of thorium oxide is above $3,000^{\circ} \mathrm{C}$. and that of beryllium oxide is above $2,400^{\circ} \mathrm{C}$. is as close an approximation as can be given at the present time. Kanolt ${ }^{2}$ has determined the melting point of magnesium oxide to be $2,800^{\circ} \mathrm{C}$. The melting point of zirconium oxide was determined by Washburn and Libman ${ }^{3}$ as approximately $2,700^{\circ} \mathrm{C}$. Podszus, ${ }^{4}$ assigned the value $2,950^{\circ}$ to $3,000^{\circ} \mathrm{C}$. to it. Washburn ${ }^{5}$ also states that the melting point of the mineral zircon (zirconium silicate) is $2,550^{\circ} \mathrm{C}$.

The exact melting point of the pure crucible material does not always determine the temperature to which the material in the cru-

' Louls Jordan, A. A. Peterson, and L. II. Phelps, Refractories for Melting Pure Metals: Iron, Nickel Platinum, Trans. Am. Electrochem. Soc., 50, p. 155; 1926.

2. W. Wanolt, Melting Points of Some Refractory Oxides, B. S. Sci. Paper No. 212; 1913.

E. W. Washburn and E. E. Libman, An A pproximate Determination of the Melting Point Diagram of the System Zirconia-silica, J. Am. Ceram. Soc., 3, p. 634; 1920.

'E. Podszus, On the Melting of and Preparation of Crucibles of Zirconium Dioxide, Z. Angew. Chemie,
"P. 17-19; 1917. 30, P. 17-19; 1917 . 
cible may be heated with safety, because so much depends upon the conditions of heating. For example, Kanolt ${ }^{6}$ states that magnesium oxide heated under reduced pressure $(0.5$ to $1.0 \mathrm{~cm}$ of $\mathrm{Hg})$ volatilized completely before it melted. When heated at atmospheric pressure in contact with carbon, it volatilizes rapidly at temperatures above $2,000^{\circ} \mathrm{C}$. Furthermore, if the metal within the crucible is heated by induction, as in a high-frequency induction furnace, the metal is always hotter than the crucible, while if heated in an electricalresistance furnace or a fuel-fired furnace where the mctal is heated by conduction of heat through the walls of the crucible, tine crucible is always at least as hot, if not hotter than the metal inside it. Slight amounts of impurity, such as bonding materials used in forming the crucibles, may lower the softening point of the crucible by as much as several hundred degrees below the melting point of the pure refractory material.

It may be of interest to note the temperatures at which crucibles of these materials have been used successfully at the National Bureau of Standards. Crucibles of zirconium oxide bonded with clay are regularly used for melting platinum and platinum-rhodium alloys containing up to 20 per cent of rhodium in a high-frequency induction furnace. The temperature of the molten metal is always over $1,770^{\circ} \mathrm{C}$. The crucibles show no signs of sof tening. They have also been used for melting rhodium, in which case the temperature attained is at least $2,000^{\circ} \mathrm{C}$.

Crucibles of commercial zirconium silicate are not at present in use for melting pure metals because of impurities introduced into the metals from the crucibles. If a purer grade of zircon were available, or where purity of the metal is not of prime importance, crucibles of this material would undoubtedly be useful at temperatures up to $2,000^{\circ} \mathrm{C}$.

Magnesium oxide crucibles prepared as described later in this paper have been used at $1,800^{\circ} \mathrm{C}$. If not in contact with carbon such crucibles probably could be used at temperatures several hundred degrees higher.

Beryllium oxide, from the results of a very few experiments, appears to be somewhat more resistant than magnesium oxide to reduction by carbon at $2,000^{\circ} \mathrm{C}$. and at atmospheric pressure.

Crucibles made of fused thorium oxide have been used to melt a platinum-iridium alloy (73 per cent Ir-27 per cent $\mathrm{Pt}$ ) whose melting point was determined to be approximately $2,200^{\circ} \mathrm{C}$. It is quite probable that crucibles of this material will stand a temperature of $2,500^{\circ} \mathrm{C}$. without softening.

In addition to refractoriness, the choice of the type of crucible material may be influenced by the means available for forming or firing the crucible. The refractory may be ground with water to form a "slip" which is then cast into plaster of Paris molds to form crucibles of the desired shapes. This method is not applicable to refractory oxides that hydrate rapidly, such as calcium or magnesium oxides. The method is, moreover, rather wasteful of material.

Another method is to moisten the refractory material with a suitable bonding solution and tamp it into a mold of the required shape. If a variety of shapes are desired it may be convenient to machine 
molds from graphite. When a number of crucibles of the same shape are required steel molds may be more convenient.

In general, it is desirable that the crucibles be fired beforehand to a temperature higher than that at which they are to be used. The Arsem vacuum furnace and the high-frequency induction furnace have been used to fire crucibles to temperatures in the range $1,700^{\circ}$ to $2,000^{\circ} \mathrm{C}$. In the latter type of furnace, a hollow cylinder of graphite placed around the refractory crucible within the inductor coil serves as a heater for the crucible.

\section{THORIUM OXIDE}

The purest grade of thorium oxide obtainable is used for the work with pure metals. The thorium oxide prepared commercially for the incandescent gas-mantle industry generally contains a small amount of sulphate which should be removed before the material is used to make crucibles in which pure metals are to be melted. Sulphates mixed with refractory oxides will under certain conditions of heating be reduced to sulphides. Experience has shown ${ }^{7}$ that metals capable of combining with sulphur will be subject to a sulphur "pick-up" when melted in a refractory oxide crucible that is contaminated with sulphides. Specially prepared thorium oxide is obtainable in a state of purity suitable for the melting of metals of highest purity. The material as purchased requires no treatment other than fusion. The best grades of thorium nitrate obtainable commercially also generally contain a small amount of sulphate, but thorium nitrate, being readily soluble in water, is more easily purified than thorium oxide, and a satisfactory grade of thorium oxide can be prepared from it:

The thorium nitrate is dissolved in water. Ammonium hydroxide added to this solution forms a precipitate of thorium hydroxide. This precipitate is washed severai times by decantation, and then dissolved in nitric acid. By repeating this cycle several times a solution of thorium nitrate can be obtained practically free of sulphate. Oxalic acid is then added to this solution to precipitate thorium oxalate. This precipitate is filtered off, washed, dried, and ignited in a muffle furnace at about $900^{\circ} \mathrm{C}$. to form thorium oxide.

\section{CRUCIBLES OF UNFUSED THORIUM OXIDE}

Thorium oxide was used at the National Bureau of Standards as a crucible material at first in the unfused form. ${ }^{8}$ The powdered thorium oxide was tamped into the form of a crucible and then heated to about $1,800^{\circ} \mathrm{C}$. This heating sintered the oxide to some extent. It was found that when using the crucibles for melting platinum in the high-frequency induction furnace, further sintering of the crucible with consequent shrinkage took place and cracks developed large enough to let molten metal through.

It is not always feasible to precalcine a crucible to a temperature higher than that at which it is to be used, nor is it practicable to cast a crucible from a molten mass of these high melting-point refractories. However, if it is possible to fuse the refractory oxide as a preliminary step, a crucible tamped from the fused and ground

\footnotetext{
7 Louis Jordan and William H. Swanger, The Properties of Pure Nickel, B. S. Jour. Research, 5, (RP257). December, 1930.

8 R. P. Neville, The Preparation of Platinum and of Platinum-Rhodium Alloys for Thermocouples, Trans. Aim. Electrochem. Soc., 43, p. 371; 1923.
} 
B. S. Journal of Research, RP327

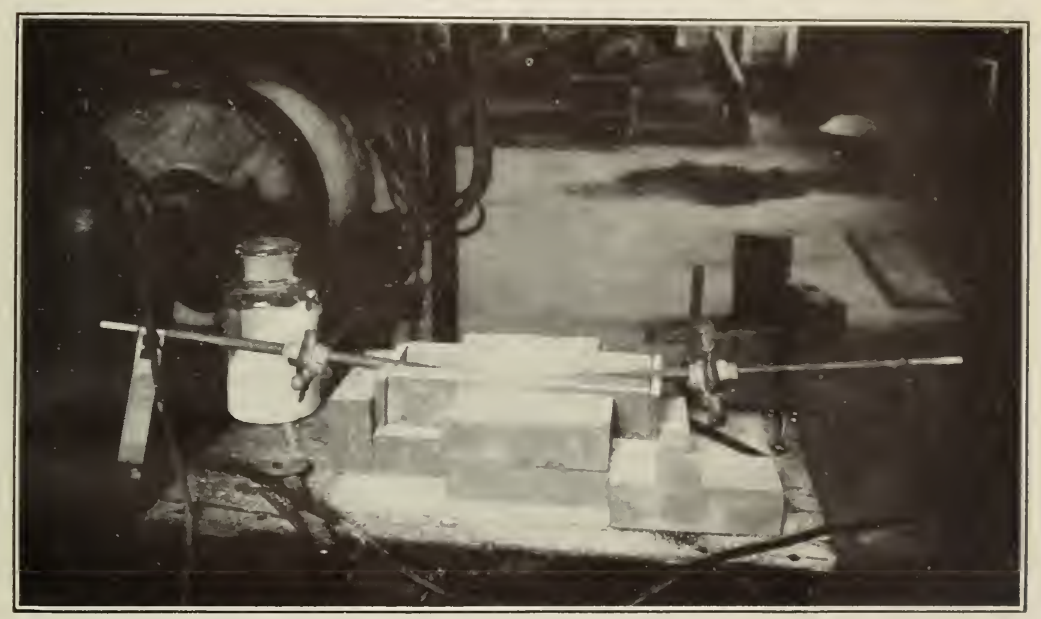

FIgURE 1.-Furnace for fusing thorium oxide 
B. S. Journal of Research, RP327

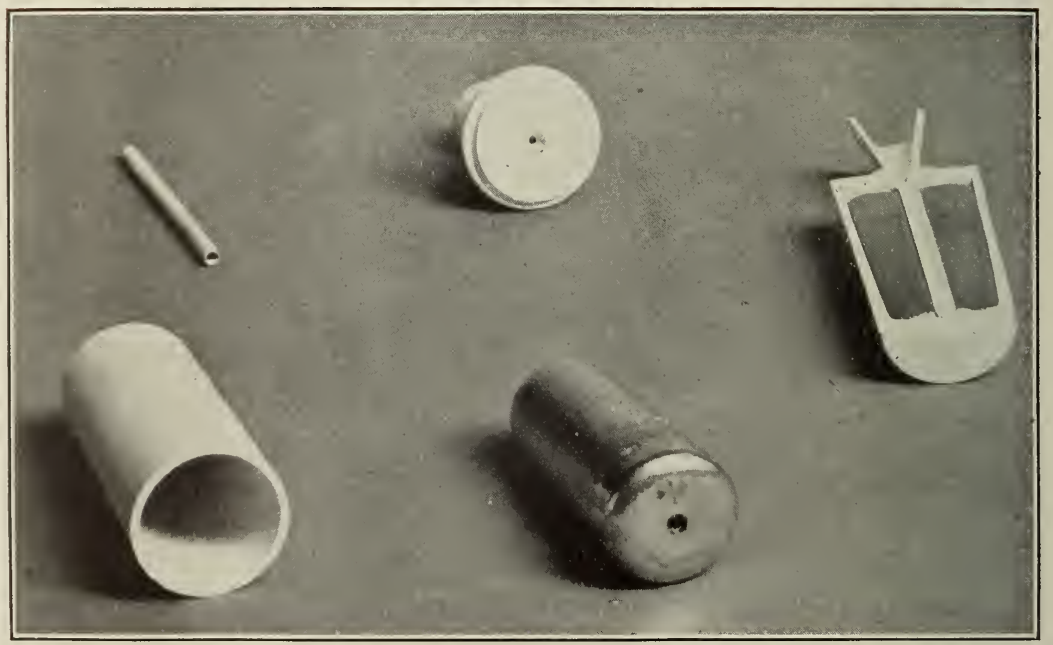

Figure 3.-Crucible and ingot as used in the determination of melting or freezing points 
oxide will not shrink a great deal when heated even to temperatures just short of its melting point. It is true that such crucibles may, from nonuniform heating, develop cracks due to unequal thermal expansion, but if the crucible is properly backed up with refractory material these cracks do not open sufficiently to let molten metal through.

\section{PROCEDURE FOR FUSING THORIUM OXIDE}

The melting point of thorium oxide is so high that the temperature of the carbon are is required to fuse it. However, if the nxide is fed into the ordinary carbon are the thoria becomes contaminated with carbon. If, however, oxygen is also fed into the arc the formation of carbide can be almost entirely prevented.

The method as developed by Fairchild and Peters ${ }^{9}$ for accomplishing this is, briefly, as follows:

The furnace, Figures 1 and 2, consists of a box about $35 \mathrm{~cm}$ long, $15 \mathrm{~cm}$ wide, and $10 \mathrm{~cm}$ deep, open at the top, made up of loose plates
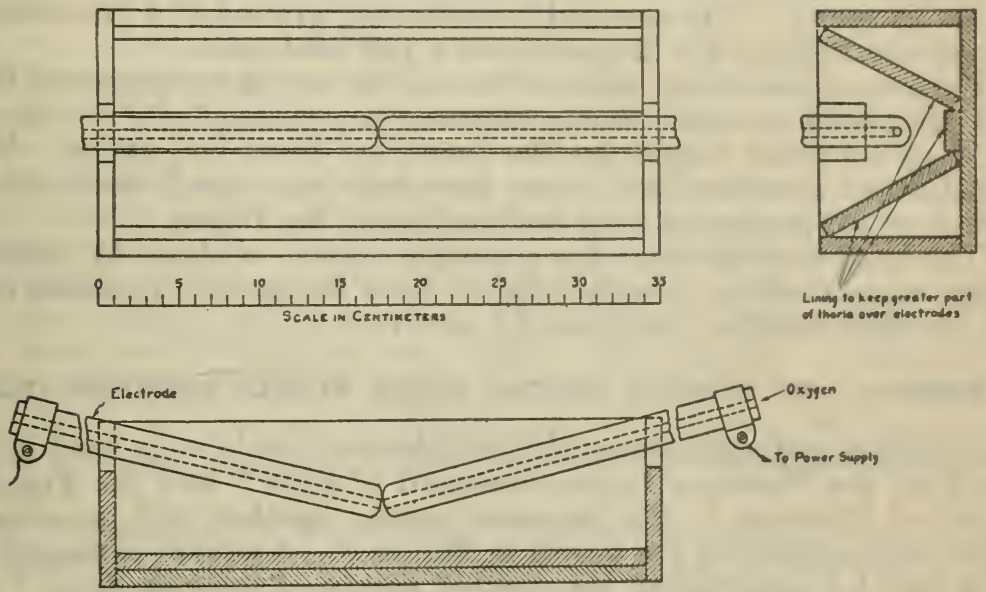

FIGURE 2.-Drawing of furnace for fusing thorium oxide

of pure graphite $1 \mathrm{~cm}$ thick laid on insulating bricks. The electrodes are two pure graphite rods $2 \mathrm{~cm}$ in diameter, $60 \mathrm{~cm}$ long, having holes $5 \mathrm{~mm}$ in diameter drilled through them lengthwise. They are placed over the long axis of the graphite box with the ends meeting at the center of the box and about $2 \mathrm{~cm}$ above the bottom. The tops of the ends of the box are cut away somewhat at the middle to allow the electrodes to lie more nearly horizontally without short circuiting against the box.

Before striking the arc, unfused thorium oxide is heaped over the junction of the two electrodes in a pile about $10 \mathrm{~cm}$ decp and a fairly rapid stream of oxygen is fed through the holes in the electrodes to maintain an oxidizing atmosphere around the arc. When the are is struck the thorium oxide near the electrodes begins to fuse. It is necessary occasionally to push the unfused thorium oxide in to the arc,

- C. O, Fairchild and M. F. Peters, U. S. Patent No. 1545951; July 14, 182. 
keeping it covered as much as possible. This may be done with a graphite rod. A 220-volt a. c. arc drawing approximately 200 amperes with about one-half ohm resistance in series with the arc has been used for this purpose.

After a pool of fused material has formed between the electrodes and the power has been cut off, the frozen thoria "glass" is picked out and the unfused particles adhering to it are knocked off. The fused thorium oxide has a glassy appearance generally with a pinkish tint which has been attributed by some to the presence of small amounts of rare earth impurities. Occasionally blackened particles apparently contaminated with carbon are found in the mass. These are picked out and treated separately. The unfused material is again heaped over the electrodes and the operation repeated.

The fused thorium oxide is ground in a steel ball mill with steel balls until all of the oxide will pass a 100-mesh sieve. The ground material is then thoroughly leached with hydrochloric acid to remove the iron introduced during the grinding and to decompose any carbides present, after which it is washed, dried, and ignited in a muffle at about $900^{\circ} \mathrm{C}$. The purified oxide is then ground in a porcelain or agate mortar until it will again pass a 100-mesh sieve.

Experience has shown that carbon can be completely removed from the blackened material that sometimes is produced along with the clear glassy fused thoria, by the treatment described above. Very satisfactory crucibles have been prepared from fused thoria which had been contaminated with carbide during the fusion.

The fused thorium oxide has a specific gravity of about 10. Refractory shapes made as described below from the ground material have an apparent specific gravity of 9.5 to 9.7 .

\section{FORMING OF SPECIAL SHAPES FROM FUSED THORIUM OXIDE}

Crucibles and sight tubes of fused thorium oxide were used in the work on the Waidner-Burgess standard of light ${ }^{10}$ and the Freezing Point of Platinum. ${ }^{11}$ The separate parts, together with a cutaway view of the assembly are shown in Figure 3. A similar arrangement was used for determining the melting points of pure rhodium ${ }^{12}$ and of some platinum-rhodium alloys.

The method of making thoria crucibles is as follows: The thorium oxide, mixed with just enough of a bonding solution to dampen it slightly is tamped into a graphite mold by means of a chisel-pointed tamping tool. The bonding solution used contains $1 \mathrm{~g}$ of thorium chloride $\left(\mathrm{ThCl}_{4}\right)$ in $5 \mathrm{ml}$ of solution. The solid plug of thorium oxide thus formed in the graphite mold is drilled while the material is still damp to form a crucible in the mold of the desired wall thickness. Crucibles having walls as thin as $1 \mathrm{~mm}$ have been made in this manner with a relatively small proportion of breakages.

The firing of these crucibles is done in two stages. The first stage or preliminary firing, to harden and shrink the crucible enough so that it may be removed from the mold and handled, is done by inclosing the mold containing the crucible, previously dried, in another graphite

${ }^{10}$ H. T. Wensel, William F. Roeser, L. E. Barbrow, and F. R. Caldwell, The Waidner-Burgess Standard of Light, B. S. Jour. Research 6, (RP 325$)$; 1931 . We, and F. R. Caldwell, The Waidner-Burgess Stand-
11 William F. Roeser, F. R. Caldwell, and H. T. Wensel, The Freezing Point of Platinum, B. S. Jour. 11 William F. Roeser, F.
Research, 6, RP 326; 1931 .

12 William H. Swanger, Melting, Mechanical Working, and Some Physical Properties of Rhodium, B. S. Jour. Research, 3, (RP127); December, 1929. 
shell and heating in air to $1,100^{\circ}$ or $1,200^{\circ} \mathrm{C}$. The purpose of the outer shell is to protect the graphite mold from burning when heated in air.

When heated in contact with carbon to temperatures much above $1,200^{\circ}$ C. thorium oxide and zirconium oxide react with carbon to form carbides. Consequently it is not possible to complete the firing of crucibles of these materials in the graphite molds in which they were formed.

After the preliminary firing the crucibles are removed from the graphite molds and are then heated to a higher temperatiure, $1,700^{\circ}$ or $1,800^{\circ} \mathrm{C}$. The crucibles are kept out of direct contact with graphite during the firing. In case the Arsem or induction furnaces are used this may be done by supporting them on a tungsten or molybdenum sheet or a block of refractory material, such as magnesium oxide or zirconium silicate.

The materials used for crucibles are also used in making sight tubes. Instead of using a relatively dry mixture, however, sufficient thorium chloride solution is added to make a thick paste. A highly polished brass rod, slightly tapered, and rounded at the small end is used as a mandrel on which to make the sight tube. The rod should be of the diameter desired for the inside of the sight tube. A suitable amount of the paste is placed on the rod near the rounded end and molded around and along the rod with the fingers. The rod, with the paste on it is then placed on a smooth, unpainted, close grained wood surface and rolled with the fingers, thus spreading the paste uniformly along the rod, at the same time drying it somewhat. If the correct consistency of the paste has been used the tube will close over the rounded end of the rod. If it does not close, a little of the wet paste can be applied and rolled until smooth. Immediately after rolling the tube it should be removed from the rod. A tube of surprisingly uniform wall thickness can be made, the thickness and length, of course, depending upon the amount and initial consistency of the paste.

The tubes are dried and fired in a manner similar to that used for the crucibles, except that the preliminary firing is dispensed with. For convenience in firing, the tubes are set upright in holes drilled in a block of thorium oxide.

Crucible covers and cones, as shown in Figure 3, are made in the same way as the crucibles. The cones are cemented to the covers with a thin paste of thorium oxide-thorium chloride solution after the preliminary firing. After the metal to be melted has been put into the crucible the separate parts are assembled as shown in Figure 3 and cemented together with a thinner paste of the same materials.

The platinum used in the work on the Waidner-Burgess standard of light ${ }^{13}$ and the freezing point of platinum ${ }^{14}$ was melted more than 150 times in a thorium-oxide crucible such as just described. The degree of contamination of the platinum by the thorium-oxide crucible may be inferred from the discussion of this point given in the paper referred to previously. ${ }^{15}$

Another method used in making crucibles of fused thorium oxide is to tamp and press the crucible material into a steel mold. A line 
sketch of a cross section of such a mold is shown in Figure 4. After this mold had had some use the walls were polished to a mirror finish and plated with chromium. It was found that there was appreciably

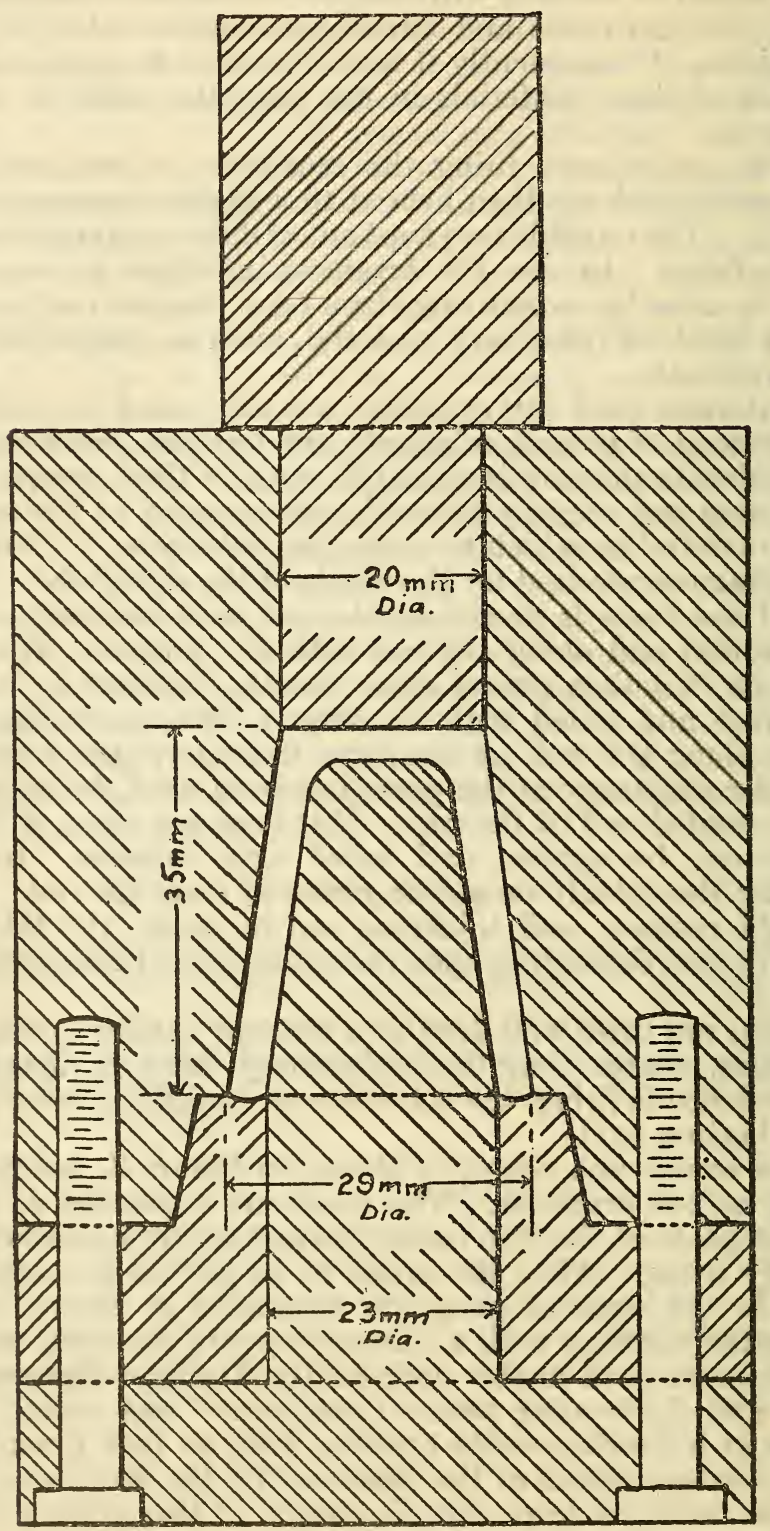

FIGURE 4.-Cross section of steel mold (assembled

less adherence of the thorium oxide to the chromium surface than to the steel surface.

Satisfactory crucibles are obtained with this steel mold when the amount of material for each crucible is controlled to within $0.5 \mathrm{~g}$ and 
the amount of bonding solution to within $0.1 \mathrm{ml}$. It requires $62.5 \mathrm{~g}$ of fused thorium oxide and $2.2 \mathrm{ml}$ of thorium-chloride solution, prepared as described above, to form a crucible in this mold. The capacity of the crucible is $7 \mathrm{~cm}^{3}$.

The crucibles after removal from the mold are dried and then fired to about $1,800^{\circ} \mathrm{C}$.

\section{MAGNESIUM OXIDE}

\section{COMMERCIAL FUSED MAGNESIUM OXIDE}

Crucibles of fused magnesium oxide can be used at temperatures considerably above that at which the crucibles have been fired without trouble due to shrinkage. This material is available commercially, ground to sizes suitable for hand tamping of the crucibles. The electrically fused or sintered magnesium oxide ground to 60 mesh and finer is moistened with a water solution of magnesium chloride before tamping. This solution is made up by dissolving an amount of magnesium chloride $\left(\mathrm{MgCl}_{2} \cdot 6 \mathrm{H}_{2} \mathrm{O}\right)$ equal to 2 per cent of the weight of the magnesium oxide needed for the crucible in a minimum amount of water. This solution is added to the batch of refractory, together with just enough additional water to moisten the refractory so that it may be tamped into the crucible mold. Emphasis is placed on the use of a chisel-pointed tool for tamping. By this means, the "rings" marking the successive additions of ground refractory may be avoided.

It is convenient to form crucibles of magnesium oxide in graphite molds or shells, because magnesium oxide does not combine with carbon to form carbides and the crucibles can be heated to $1,800^{\circ} \mathrm{C}$. while held in the molds in which they were formed.

Such crucibles may also be tamped in pasteboard cylinders such as the ordinary mailing tubes or cases. In firing the crucibles the paper cases are allowed to burn away. Ordinarily a wood or metal mandrel is used as a core around which the crucible is formed and is, of course, removed before the crucible is fired.

\section{CHEMICAL REAGENT GRADE OF MAGNESIUM OXIDE}

The commercial fused magnesium oxide is not of sufficient purity for use with pure metals, as was found in previous work at the $\mathrm{Na}$ tional Bureau of Standards. ${ }^{16}$ The more pure "C. P." or chemical reagent grade of unfused magnesium oxide can be sintered to form very hard and dense crucibles that have almost a porcelainlike body or texture. This oxide is a very light and fluffy powder and shrinks to about half its original volume when heated to $1,600^{\circ}$ to $1,800^{\circ} \mathrm{C}$. Consequently it is necessary to calcine the powder before forming a crucible. For this purpose it may be lightly tamped into a convenient graphite shell, preferably around a small core or mandrel, or pressed into briquets. A small amount of alcohol or petroleum ether mixed with the powder improves its tamping properties. The uncalcined powder which has been exposed to the air for some time contains about 2.5 per cent of carbon dioxide. It is advisable to remove

16 See footnote 1, p. 1132.

$55946-31-15$ 
this by heating in an ordinary muffle to about $900^{\circ} \mathrm{C}$. before attempting the calcination at the higher temperature, especially if the latter heating is to be done in the Arsem furnace; otherwise the sudden evolution of carbon dioxide at the reduced pressure of the Arsem furnace may blow the oxide out of its container.

The calcined oxide is broken up and ground in a porcelain ball mill to pass a 100-mesh screen. This material is mixed with a 2 per cent solution of magnesium chloride ( $2 \mathrm{~g} \mathrm{MgCl}_{2} \cdot 6 \mathrm{H}_{2} \mathrm{O}$ in $100 \mathrm{ml}$ $\mathrm{H}_{2} \mathrm{O}$ ) which is more dilute than the bonding solution used with the fused magnesium oxide. Only enough of this solution is used to moisten the oxide so that it can be tamped. The crucibles are most conveniently made by tamping them in graphite molds of the required shape and then firing them in the same mold to $1,600^{\circ}$ to $1,800^{\circ} \mathrm{C}$. If the preliminary calcining of the oxide was carried to about $1,700^{\circ} \mathrm{C}$. and the tamping was well done, the linear shrinkage of these crucibles during the final firing is about 4 per cent.

Crucibles of this previously calcined "C. P." magnesium oxide are also made in the steel mold described above under "Thorium oxide crucibles." The same precautions as to tamping and accurate measuring of the quantity of refractory and of bonding solution apply. Generally, it requires 21.5 to $22.0 \mathrm{~g}$ of the previously calcined magnesium oxide and $2.0 \mathrm{ml}$ of the 2 per cent magnesium chloride solution to fill the mold. The amount of oxide varies slightly according to the temperature at which it was calcined; that is, the higher the temperature the denser the material becomes. The apparent specific gravity of these "pure" magnesium oxide crucibles is about 3.5 . The specific gravity of fused magnesia is generally given as 3.5. to 3.7 .

Crucibles of this purer grade of magnesium oxide have been used at the National Bureau of Standards for melting pure metals, such as iron, nickel, gold, platinum, and platinum-rhodium alloys, without appreciable contamination of the metals by the refractory. It has been found that platinum melted in vacuo (pressure of 1 to $2 \mathrm{~mm}$ of mercury) in a crucible of this type gave a thermal electromotive force against the bureau's platinum standard, $\mathrm{Pt} 27$, of +50 microvolts at $1,200^{\circ}$ C. Samples from the same lot of platinum melted in such a crucible open to the air gave a thermal electromotive force of +6 to +10 microvolts against the standard at $1,200^{\circ} \mathrm{C}$. Spectrographic examination showed the presence of magnesium in the vacuum melted platinum and its absence from the platinum melted in a similar crucible open to the atmosphere. It has not yet been established whether the magnesium in the platinum was a product of the dissociation of magnesium oxide at the high temperature and low pressure or the result of a reducing action of oil vapors from the vacuum pump on the hot magnesium oxide.

\section{ZIRCONIUM OXIDE}

\section{1. "SLIP-CAST" CRUCIBLES}

Crucibles of fused zirconium oxide for the melting of platinum and platinum-rhodium alloys are made essentially as described in a previous report. ${ }^{17}$ Briefly, the method is as follows: Commercial electrically fused оr sintered zirconia, ground to about $100-$ mesh and 
finer, is first washed with hydrochloric acid to remove iron and then roasted in an open muffle at about $800^{\circ}$ to $900^{\circ} \mathrm{C}$. to remove carbon. A casting "slip" is then prepared by grinding for about eight hours in a porcelain ball mill with flint pebbles, a batch of the following proportions: $1,000 \mathrm{~g}$ purified zirconia, $40 \mathrm{~g}$ china clay, and $500 \mathrm{ml}$ water. Crucibles are formed by pouring this slip into plaster of Paris molds. As water is absorbed from the slip into the walls of the mold, the mold is kept filled with more of the slip. When sufficient solid has formed on the inside wall of the mold the excess slip is poured out. The cast form continues to shrink and soon can be remored froin the mold. It is then dried, first in the air, then in an oren at $120^{\circ}$ to $150^{\circ} \mathrm{C}$. and finally fired to about $1,700^{\circ} \mathrm{C}$, keeping in mind that the crucibles must be kept from direct contact with graphite at temperatures above about $1,200^{\circ} \mathrm{C}$.

The linear shrinkase of these slip-cast crucibles is about one-third. About half of this shrinkage takes place during the drying and the remainder during firing. Consequently the loss due to cracking is considerable.

\section{TAMPED AND PRESSED CRUCIBLES}

By tamping the purified zirconium oxide in graphite molds, or by tamping and pressing in a steel mold, crucibles may be made with a smaller proportion of losses from cracking. If made in a graphite mold, the crucibles can not be fired in the mold beyond $1,200^{\circ} \mathrm{C}$. After a preliminary firing at this temperature they are removed from the mold and fired to about $1,700^{\circ} \mathrm{C}$., in the same manner as the "slip-cast" crucibles. China clay is not added to the zirconium oxide in this method, but a solution of zirconium chloride $\left(2 \mathrm{~g} \mathrm{ZrCl}{ }_{4}\right.$ in 100 $\mathrm{ml}$ water) may be used to moisten the zirconium oxide and act as a binder. (Thorium chloride and magnesium chloride solutions of similar concentration apparently serve equally well as binders.) The linear shrinkage of the tamped crucibles is about the same as that of the magnesuim oxide crucibles described above, viz, about 4 per cent. They are as hard and strong as the slip-cast zirconia crucibles and have been used at somewhat higher temperatures without softening, since no clay was used to bond them.

The commercial fused or sintered zirconium oxide contains a small amount of silica and more silica is introduced by the china clay in preparing the "casting-slip." The silica does not affect the purity of platinum melted in the cast crucibles when the melting is done in air, but does contaminate the platinum very severely when the melting is done in vacuo.

\section{BERYLLIUM OXIDE}

Pure beryllium oxide is not produced commercially. Through the courtesy of the Brush Laboratories (Inc.), of Cleveland, Ohio, a small quantity was supplied to the National Bureau of Standards, sufficient to permit a few observations to be made of its behavior as a refractory material. The oxide was apparently of high purity, very light and fluffy and very white. It was heated in a graphite container in the Arsem furnace to about $1,700^{\circ} \mathrm{C}$, and in the high-frequency induction furnace to about $1,800^{\circ} \mathrm{C}$. Like magnesium oxide, it does not combine with carbon at high temperatures to form carbides. It appeared to volatilize less rapidly than magnesiun oxide under these 
conditions. Like the "C. P." grade of magnesium oxide, it shrank to about half its original volume when calcined in graphite at $1,700^{\circ}$ to $1,800^{\circ} \mathrm{C}$.

The calcined beryllium oxide was broken up and ground to pass a 100 -mesh screen. Several crucibles were tamped and pressed in the steel mold arleady described. A solution of beryllium chloride ( $4 \mathrm{~g} \mathrm{BeCl}$ in $100 \mathrm{ml}$ water) was used to moisten the beryllium oxide. The crucibles were fired in an Arsem furnace to $1,700^{\circ} \mathrm{C}$. They were beautifully white, extremely strong and hard, and very resistant to thermal shock. The apparent specific gravity of the crucibles was about 3.0 .

A melt of pure platinum was made in one of these crucibles in the high-frequency induction furnace. The metal was allowed to freeze in the crucible, and after removal of the button, except for a layer of volatilized platinum on the wall, it could hardly be seen that the crucible had been used.

Pure platinum melted in a beryllium oxide crucible in vacuo (pressure of 1 to $2 \mathrm{~mm}$ of $\mathrm{Hg}$ ) proved to have alloyed with beryllium, a result similar to that obtained when using a magnesium oxide crucible. The vacuum-melted platinum gave a thermal electromotive force of +50 microvolts against the platinum standard, $\mathrm{Pt}$ 27 , at $1,200^{\circ}$ C. Spectrographic examination of the platinum disclosed the presence of beryllium. Another sample from this same lot of purified platinum sponge melted in air in a zirconium oxide crucible gave a thermal electromotive force of +4 microvolts to the platinum standard, Pt 27. The sample melted in air in the beryllium oxide crucible gave a thermal electromotive force of -7 microvolts against the standard.

Actual determinations of the amounts of thorium, magnesium, or beryllium introduced into pure platinum when melted in vacuo in crucibles of thorium, magnesium, or beryllium oxides, respectively, have not been made.

\section{SUMMARY}

1. The oxides of thorium, magnesium, zirconium, and beryllium can be used as refractories in which to melt metals of the highest purity without detrimental contamination of the metal by the refractory.

2. Thorium oxide is the most refractory of these four oxides. Its melting point has not been determined, but is generally believed to be above $3,000^{\circ} \mathrm{C}$. The oxide is fused in the carbon arc, oxygen being fed into the arc to prevent the formation of thorium carbide. Crucibles prepared from this fused material have been used at temperatures to $2,200^{\circ} \mathrm{C}$.

3. Magnesium oxide volatilizes rapidly at temperatures between $2,000^{\circ} \mathrm{C}$. and its melting point $\left(2,800^{\circ} \mathrm{C}\right.$.), especially under reduced pressure or in contact with carbon. Crucibles of magnesium oxide have been used at temperatures up to $1,800^{\circ} \mathrm{C}$.

4. Crucibles of commercial zirconium oxide containing a small amount of silica are used only under oxidizing conditions and at atmospheric pressure, but are safely used under these conditions at temperatures up to $2,000^{\circ} \mathrm{C}$. 
5. A few experiments with beryllium oxide indicate that it does not volatilize as rapidly in contact with carbon at $2,000^{\circ} \mathrm{C}$. as does magnesium oxide, and that very satisfactory crucibles for high-temperature service may be formed from it.

6. Crucibles of any of the four oxides may be formed by tamping and pressing in a steel mold. Special shapes are made by tamping the refractory into graphite molds. Crucibles of zirconium oxide were made by casting a "slip" into plaster of Paris molds.

7. The crucibles may be fired at $1,600^{\circ}$ to $1,800^{\circ} \mathrm{C}$. in an $\mathrm{Arsem}$ furnace. Magnesium and beryllium oxides do not furm carbides when heated to these temperatures in contact with carbon. Thorium and zirconium oxides must be kept out of direct contact with carbon at temperatures above $1,200^{\circ} \mathrm{C}$.

Washington, June 30, 1930. 